\title{
A compreensão é uma grande porca acinzentada - Uma leitura sobre a busca da linguagem em $A$ obscena senhora $D$, de Hilda Hilst.
}

Tatiana Rodrigues Franca ${ }^{1}$

Ele os pune por terem querido construir à altura dos céus? Por terem querido alcançar o mais alto, até o altíssimo? Talvez, sem dúvida por isso, mas incontestavelmente por terem querido assim se fazer um nome, dar a eles mesmos o nome, construir eles mesmos seu próprio nome [...] (Derrida, 2006, p. 17).

La esencia lingüística de las cosas es su lengua; esta proposición aplicada al hombre, dice: la esencia lingüística del hombre es su lengua. Es decir que el hombre comunica su propia esencia espiritual en su lengua. Pero la lengua de los hombres habla en palabras (Benjamin, 1987, p. 141).

A narrativa de $A$ obscena Senhora $D$ é atravessada, ponta a ponta, pelas inquietações da personagem Hillé. De todas elas - que sobretudo tematizam a obra das "metafísicas" às "dúvidas teológicas" , como propõe Alcir Pécora (In:Hilst, 2001), há uma que se traduz em busca incessante:

\footnotetext{
${ }^{1}$ Universidade Federal de Goiás. Brasil

Brasiliana - Journal for Brazilian Studies. Vol. 1, n.1 (Sept. 2012). ISSN 2245-4373.
} 
Como foi possível ter sido Hillé, vasta, afundando os dedos na matéria do mundo, e tendo sido, perder essa que era, e ser hoje quem é?

Quem a mim me nomeia o mundo? Estar aqui no existir da Terra, nascer, decifrar-se, aprender a deles adequada linguagem, estar bem (Hilst, 2001, p. 24, grifos nossos).

Ou seja, a preocupação principal passa pelo desejo de autoconhecimento que, no entanto, só é alcançável via representação verbal. Através da significação dada pela palavra, pela capacidade de nomear, é que se chega a uma identidade, mas, para tanto, "é preciso aprender a linguagem", como diz a personagem central da narrativa, Hillé.

A preocupação de Hillé em poder nomear a si e ao que sente está ligada à capacidade de poder criar ou gerir o universo. Portanto, da mesma forma com que se preocupa em encontrar o seu próprio nome como possibilidade de inserir sentido à própria existência, procura renomear Deus como forma de torná-lo possível à fé. Interessante notar que na primeira tentativa, ela se autodefiniu pela negação:

[...] eu Hillé também chamada por Ehud A Senhora D, eu Nada, eu Nome de Ninguém, eu à procura da luz numa cegueira silenciosa, sessenta anos à procura do sentido das coisas (Hilst, 1999, p.19).

A recusa de uma denominação também pode estar ligada à recusa da linguagem. Vale voltar à primeira epígrafe, que remete ao Torres de Babel², de Jacques

\footnotetext{
${ }^{2}$ Embora Derrida utilize o mito da Torre de Babel para pensar questões em torno da tradução especificamente, neste trabalho serão válidas suas reflexões para pensar metaforicamente a busca da linguagem em Hilst como um ato tradutório.
}

Brasiliana - Journal for Brazilian Studies. Vol. 1, n.1 (Sept. 2012). ISSN 2245-4373. 
Derrida. Neste texto, o pensador francês percorre a história bíblica considerando primeiramente a etimologia do nome Babel e os comentários encontrados no Dictionnaire philosophique, de Voltaire, cuja consideração linguística de que $B a$ seria traduzido por "pai" e Bel seria "Deus", leva a inferir tanto que Babel seria, então, "cidade de Deus", quanto faz soar também que pode significar "confusão". Diante dessa aporia de nomes:

[...] Babel não quer dizer apenas confusão no duplo sentido dessa palavra, mas também o nome do pai, mais precisamente e mais comumente, o nome de Deus como nome do pai. A cidade carregaria o nome de Deus o pai e do pai da cidade que se chama confusão. Deus, o Deus teria marcado com seu patrônimo um espaço comunitário, essa cidade onde não se pode mais se entender (Derrida, 2006, p. 14).

Como nos conta a mitologia cristã, a construção da Torre foi motivada pela ambição dos homens que queriam criar uma língua própria, ou melhor, se "fazerem um nome", no intuito de não "serem dispersados sobre a face da terra" (Derrida, 2006, p. 15). Por isso, o castigo divino multiplica as letras ${ }^{3}$ e cria a confusão entre os homens, que deixam de falar uma única língua. Curiosamente, a mesma cólera que reivindica o seu direito à origem dos nomes dá origem à multiplicidade de palavras criadas a partir de então:

Dando seu nome, dando todos os nomes, o pai estaria na origem da linguagem e esse poder pertenceria de direito a Deus o pai. E o nome de Deus o pai seria o nome dessa origem das línguas. Mas é também esse

\footnotetext{
${ }^{3}$ Ver Eco, 2002, p. 47.
}

Brasiliana - Journal for Brazilian Studies. Vol. 1, n.1 (Sept. 2012). ISSN 2245-4373. 
Deus que, no movimento de sua cólera [...], anula o dom das línguas, ou ao menos o desune, semeia a confusão entre seus filhos e envenena o presente (Gift-gift). É também a origem das línguas, da multiplicidade dos idiomas, dito de outra maneira, daquilo que se chama correntemente de línguas maternais (Derrida, 2006, p.14).

Desse jeito, a partir daí, a relação entre os homens só é possível na/pela tradução "Ele [Deus] impõe e interdiz ao mesmo tempo a tradução", diz Derrida. Ainda de acordo com essas considerações:

Essa história conta, entre outras coisas, a origem da confusão das línguas, a multiplicidade dos idiomas, a tarefa necessária e impossível da tradução, sua necessidade como impossibilidade (Derrida, 2006, p. 21).

É dessa contradição entre necessidade e impossibilidade que trata a pergunta que dá início a esse trabalho: "Quem a mim me nomeia o mundo?". Vimos, depois da desconstrução de Babel, o ato de nomear como um ato tradutório, já que a língua original fora perdida. A questão central de Hillé é, portanto, ao nomear as coisas, ou recusar suas nomenclaturas possíveis, buscar sua essência, seu sentido. Desse jeito, Deus adquire vários nomes dados por ela: Este, O Luminoso, O Vívido, O Nome, PorcoMenino Construtor do Mundo, assim como ela mesma se ausenta do próprio nome, ou quiçá, mesmo o negue, em função da incógnita letra " $\mathrm{D}$ ". Dessa forma, ao assumir o nome-enigma senhora $D$, ou, mais tarde, ao se declarar metamorfoseada em búfalo, zebu, girafa, Hillé tenta (re) criar a si mesma através da palavra e daí cria a possibilidade de 
reorganizar o mundo - no princípio era o verbo, declara o apóstolo João - e a organização a partir do verbo gera a possibilidade de chegar à compreensão - a "procura da luz", a que Hillé se dedica, chegaria, então, a seu termo:

Não pactuo com as gentes, com o mundo, não há um sol de ouro no lá fora, procuro a caminhada sem fim, te procuro, vômito, Menino-Porco, ando galopando desde sempre búfalo zebu girafa, derepente despenco sobre as quatro patas e me afundo nos capins resfolegando, sou um grande animal, úmido, lúcido, te procuro ainda, agora não articulo, também não sou mudo, uns urros, uns finos fortes escapam da garganta, agora eu búfalo mergulho, uns escuros [...] sendo girafa te procuro mais perto, lambedura acontecível isso de Hillé ser búfalo zebu girafa, acontecível isso de alguém ser muito ao mesmo tempo nada, de olhar o mundo como quem descobre o novo, o nojo, o acogulado, e olhando assim ainda ter o olho adiáfano, impermissível, opaco (Hilst, 2001, p. 2527).

As imagens surreais "acontecíveis" são a busca pela representação, ou a procura por uma similitude ${ }^{4}$ entre Hillé e o mundo, mas que esbarra, porém, numa

\footnotetext{
${ }^{4} \mathrm{O}$ termo é de Michel Foucault, no seu As palavras e coisas, texto que trata a mesma questão em que mergulhamos aqui sob um outro ângulo. Segundo ele, a representatividade e a similaridade tiveram um importante papel na construção do saber no Ocidente. De acordo com isso, [...] a linguagem se dá por tarefa restituir um discurso absolutamente primeiro que, no entanto, ela só pode enunciar acercando-se dele, tentando dizer a seu propósito coisas semelhantes a ele, e fazendo assim nascer, ao infinito, as fidelidades vizinhas e similares da interpretação [...] porque a semelhança não pode ser conhecida por si mesma, já que os signos não podem ser outra coisa senão similitudes (Foulcault, 2002, p. 56). Sabe-se que, no entanto, a representatividade vai perdendo essa fibra de realidade, e isso se pronuncia principalmente através da palavra: Mas, se a linguagem não mais se assemelha imediatamente às coisas que ela nomeia, não está por isso separada do mundo; continua, sob uma outra forma, a ser o lugar das revelações e a fazer parte do espaço onde a verdade, ao mesmo tempo, se manifesta e se enuncia.[...] É antes a figura de um mundo em via de se redimir, colocando-se, enfim, à escuta da verdadeira palavra (Foulcault, 2002, p. 50).
}

Brasiliana - Journal for Brazilian Studies. Vol. 1, n.1 (Sept. 2012). ISSN 2245-4373. 
aporia: a linguagem se comunica ao infinito e a palavra - como cada língua - se revela insuficiente, pois o signo constrói sentido em relação diacrítica, isolado, porém, leva ao implacável silêncio. Por isso, se é "muito" e ao mesmo tempo "nada", pode-se ver tudo, mas olho permanece "adiáfano", "opaco". E, nessa impossível - e necessária - tradução, para voltar a Derrida, na impossibilidade de haver uma ligação transparente entre significante e significado (ainda que seja nas relações dentro de uma mesma língua), Hillé recorre, então, à linguagem babélica e ao fluxo de consciência:

Casa da Porca, assim chamam agora a minha casa, fiquei mulher desse Porco-Menino Construtor do Mundo, abro a janela nuns urros compassados, espalho roucos palavrões, giro as órbitas atrás da máscara, não lhes falei que recorto uns ovais feitos de estopa, ajusto-os na cara e desenho sobrancelhas negras, olhos, bocas brancas abertas?(...) Lixo as unhas no escuro, escuto-me a mim mesma, há uns vivos lá dentro além da palavra, expressam-se mas não compreendo, pulsam, respiram, há um código no centro, um grande umbigo, dilata-se, tenta falar comigo, espio-me curvada, winds flowers astonished birds, my name is Hillé, mein name madame $D$, Ehud is my husband, mio marito, mi hombre, o que é um homem? (Hilst, 1999, p. 20 - 22, grifos meus).

O potencial criador do verbo permite que haja uma certa união entre a língua e as coisas: o homem nomeia a si a aos seus semelhantes, determinando-lhes a essência. Não por acaso, a etimologia da palavra "substantivo" tem a mesma raiz que 
"substância", por isso é essa a classe de palavras que nomeia os seres, uma vez que o nome aponta para a essência daquilo que designa. Mas a "comunicação" também se dá na ausência, na impossibilidade de compreender (lembrando que há duas acepções possíveis e que devem ser percebidas aqui: "compreender" como "abarcar" e "compreender" como "entender") a totalidade do que se quer representar, o significado é passado adiante, aos confins da linguagem, como diz Hillé: "há uns vivos lá dentro além da palavra, expressam-se mas não compreendo". É aí que se insere Deus, como veremos mais adiante.

Walter Benjamin, no texto Sobre el lenguaje en general y sobre el lenguaje de los hombres, entende "linguagem" como toda forma de comunicação de conteúdos espirituais e, por causa disso, ela está relacionada à essência daquilo que nomeia. No entanto, há dois tipos de linguagem, a dos homens, que, por ter recebido o sopro de Deus, têm a capacidade de criar, e a dos objetos, ou das coisas, que é muda por pertencer à mera enunciação. Márcio Seligmann-Silva, no seu Ler o livro do mundo, nos aclara a percepção benjaminiana:

[...] a essência espiritual dos objetos deixa-se comunicar apenas de modo deficiente na sua "essência lingüística" pois os objetos são mudos e, portanto, não há uma sobreposição neles entre a essência espiritual e a linguagem. Já no homem, essa essência corresponde às suas palavras, e ainda: o homem expressa a sua essência espiritual apenas na medida em que nomeia as demais coisas. "porque a essência espiritual do homem é a linguagem mesma, portanto ele não pode comunicar-se através dela, mas sim nela. A suma totalidade intensiva da linguagem como essência

Brasiliana - Journal for Brazilian Studies. Vol. 1, n.1 (Sept. 2012). ISSN 2245-4373. 
espiritual é o nome. O homem é aquele que denomina, daí reconhecer-se que a linguagem pura fala a partir dele" (Seligmann-Silva, 1999, p. 81).

A linguagem, ou ainda o nome, como meio correspondente espiritual do homem tem seu fim último na possibilidade de nomear. Dar nome às coisas significa realizá-las em completude, então, o nome senhora $D$, torna-se um enigma, pois a inicial "D", de "derrelição", também é a inicial de "dúvida" e, não por acaso, de "Deus". E faz sentido pensar em um "abandonar-se na dúvida" como sendo um "abandonar-se na fé". $\mathrm{Ou}$, pelo menos, é via abandono que existe a possibilidade de encontrar o sentido da vida, tão meticulosamente pesquisado por ela, já que Deus é o nome impronunciável por definição e, de acordo com os cabalistas, não possui nenhum sentido ou significado concreto $^{5}$ :

Olha Hillé a face de Deus

Onde onde?

Olha o abismo e vê

Eu vejo nada

Debruça-te mais agora

Só névoa e fundura

É isso. adora-O. Condensa névoa e fundura e constrói uma cara (Hilst, 2001, p. 47)

5 Ver Scholem, 1972. É a esta altura que A obscena senhora $D$ começa a apontar para uma convergência com a teoria cabalística. A impossibilidade de nomear Deus - daí rebaixá-lo a "porco" ou mesmo ao (re) elevá-lo a "Luminoso" - é latente em todo o texto de Hilst.

Brasiliana - Journal for Brazilian Studies. Vol. 1, n.1 (Sept. 2012). ISSN 2245-4373. 
Abismar-se e não ver nada: isso é Deus. Também é o abandono e a incapacidade de poder construir sentido das coisas através do signo, da mera representação. Voltando ao texto de Seligmann-Silva:

\begin{abstract}
Além disso, como Benjamin acrescenta, a linguagem dos homens diferencia-se da linguagem (imperfeita) das coisas justamente porque ela possui o som que a Bíblia descreve como o sopro,ou seja, ao mesmo tempo vida, espírito e linguagem, insuflado por Deus no homem (Seligmann-Silva, 1999, p. 82).
\end{abstract}

Já que a linguagem do homem é perfeita na sua magia porque a ele foi dado o sopro de Deus (assim ele foi transformado do barro), é ela enquanto meio que ela irá levá-lo ao conhecimento:

que se deite aqui e sinta comigo os murmúrios, palavras que deslizam numa teia, uma estacou agora, e vagarosamente uns fios brilhosos se torcem à sua volta, meu deus, vão recobri-la, que palavra? que palavra? CONHECIMENTO, Hillé, ainda posso vê-la, CONHECIMENTO sendo sufocada por uns fios finos e de matéria densa (Hilst, 2001, p. 70).

Na linguagem divina não há separação entre nome e objeto, aí se dá a possibilidade de conhecimento total, mas para os homens, para Hillé, há a angustiante certeza de que, tão logo se vislumbre esse conhecimento, tão mais imediatamente ele é recoberto, ou "sufocado por uns fios finos e matéria densa". Se o homem exerce seu 
poder sobre a natureza através da possibilidade de nomear6, é lembrado a ele que "a capacidade nomeadora que o homem recebe é um reflexo do verbo divino, mas possui uma essência limitada diante da infinidade criadora deste verbo" (Seligmann-Silva, 1999, p. 83) e, enquanto reflexo, a ela cabe somente a tradução. Ora, se a tradução se dá como necessidade e impossibilidade, como vimos em Derrida, e se pensarmos na tradução como a busca de Hillé "pelo sentido das coisas" (tomando aqui essa busca inclusive por uma linguagem plena) fica nítida nas suas palavras a imensa insatisfação:

A vida foi isso de sentir o corpo, contorno, vísceras, respirar, ver, mas nunca compreender. porisso é que me recusava muitas vezes. queria o fio lá de cima, o tenso que o OUTRO segura, o OUTRO, entendes? Que OUTRO mamma mia?

DEUS DEUS, então tu ainda não compreendes?(Hilst, 2001, p. 53).

A compreensão tão cara a Hillé pode ser vista como o desejo profundo de que a "tradução" se desse plenamente, o fio seguro pelo "outro", do outro lado, mas como isso é impossível, a sua compreensão demonstra que a língua também é o incomunicável. Voltando ao ensaio de Seligmann-Silva:

\footnotetext{
${ }^{6}$ No texto de Benjamin: Toda naturaleza, en cuanto se comunica, se comunica en la lengua, y por lo tanto, en última instancia, en el hombre. Por elle el hombre es señor de la naturaleza y puede nombrar las cosas. Sólo a través de la esencia lingüística de las cosas llega el hombre desde sí mismo al conocimiento de éstas: en el nombre. La creación de Dios se completa cuando las cosas reciben su nombre del hombre, de quien en el nombre habla sólo la lengua. Se puede definir el nombre como la lengua de la lengua (con tal de que el genitivo no signifique la relación del medio sino de lo central), y en este sentido ciertamente, puesto que habla en el nombre, el hombre es el sujeto de la lengua y por ello mismo el único. En la designación del hombre como parlante(que es evidentemente, por ejemplo, según la Biblia, el dador de nombres: "Toda denominación que el hombre pusiera a los seres vivientes, tal fuese su nombre”) muchas lenguas encierran en sí este conocimiento metafisico (Benjamin, 1987, p. 143).
}

Brasiliana - Journal for Brazilian Studies. Vol. 1, n.1 (Sept. 2012). ISSN 2245-4373. 
A perda da capacidade de traduzir a linguagem das coisas na linguagem dos nomes funda [...] o nascimento da pluralidade das línguas e o fim da linguagem única, do saber perfeito típico da linguagem paradisíaca (Seligmann-Silva, 1999, p. 85).

É possível pensar nas inquietações de Hillé como parte dessa perda. $\mathrm{Na}$ sua relação com o marido Ehud, de quem mais tarde ela se tornou viúva, sempre havia uma lacuna e, como se a linguagem dela para ele não fosse suficiente, como se a comunicação entre eles não fosse perfeita, ela passa a habitar no vão da escada:

Senhora D, é definitivo isso de morar no vão da escada? Você está me ouvindo Hillé? Olhe, não quero te aborrecer, mas a resposta não está aí, ouviu? Nem no vão da escada, nem no primeiro degrau aqui de cima, será que você não entende que não há resposta?(Hilst, 2001, p. 19).

Ehud assegura Hillé de que "não há resposta" e essa certeza nos lembra o terceiro nível em que se desdobra a língua, segundo Benjamin, a "língua decaída", a que separou a relação entre nome e conhecimento (sendo esta a procurada por Hillé), marcada "por uma relação externa com as coisas":

Com a "queda", não apenas a natureza deixou de poder se comunicar como também a palavra decaída, o signo, marcado pelo fato de "significar", de indicar algo fora de si, de exigir uma tradução [...] indica na verdade a própria incompletude desta linguagem - língua heterônoma, o que revela ao mesmo tempo a situação de "separação" do 
homem com relação ao "estado pré-babélico", ou se quiser, "préqueda". A pluralidade das línguas nasce dessa incapacidade de uma leitura única, imediata do mundo [...] (Seligmann-Silva, 1999, p. 86).

A "incompletude da linguagem" é, para Hillé, a incompreensão. Isso fica claro na forma como ela se dirige a Deus:

Desamparo, Abandono, assim é que nos deixaste. Porco-Menino, menino-porco, tu alhures algures acolá lá longe no alto aliors, no fundo cavucando, inventando sofisticadas maquinarias de carne, gozando o teu lazer: que o homem tenha um cérebro sim, mas que nunca alcance, que sinta amor sim mas nunca fique pleno, que intua sim meu existir mas que jamais conheça a raiz do meu mais ínfimo gesto, que sinta paroxismo de ódio e de pavor a tal ponto que se consuma e assim me liberte [...] (Hilst, 2001, p. 36).

A senhora D deseja o inalcançável, o inefável, o que nos remete ao caráter simbólico da linguagem, também trabalhado por Benjamin e discutido por SeligmannSilva:

[...] Benjamin elabora uma reflexão acerca do caráter simbólico desta linguagem. Pois ela "não é apenas comunicação do comunicável, mas ao mesmo tempo símbolo do não-comunicável" (II 156). Este "lado simbólico da linguagem" persiste como um resquício (eco) do verbo divino no homem, assim como a linguagem da natureza ainda se comunica com ele através da sua linguagem muda, vestígio do verbo 
criador. A palavra divina permanece, portanto, [...] como o fator de unidade de todas as línguas [...] e entre a linguagem da natureza e a humana (Seligmann-Silva, 1999, p. 86).

E é enquanto símbolo dessa linguagem perdida que vemos aqui a temática da morte, presente em toda A obscena Senhora D. Quer falando da morte do marido, da de seu pai, ou da própria, Hillé usa dessa imagem para refletir sobre a perda de significado e também sobre a possibilidade de, na morte, haver uma abertura para novas significações (ou, quiçá, linguagens significativas). Daí a importância do poema que serve de epígrafe à obra:

Para poder morrer

Guardo insultos e agulhas

Entre as sedas do luto.

Para poder morrer

Desarmo as armadilhas

Me estendo entre as paredes

Derruídas.

Para poder morrer

Visto as cambraias

E apascento os olhos

Para novas vidas.

Para poder morrer apetecida 
Me cubro de promessas

Da memória.

Porque assim é preciso

Para que tu vivas (Hilst, 2001, p. 15).

Aparentemente, e devido a presença de um interlocutor, o poema é escrito para pensar a morte de alguém, o que até faz muito sentido, já que a narrativa do livro trata da morte de Ehud e da do pai de Hillé quase todo o tempo. Contudo, é possível perceber que a situação é bastante simbólica dentro do aspecto que vimos desenvolvendo até aqui. Primeiro, porque temos percebido como a falência da representação perfeita das palavras incomoda Hillé, depois, pelas reflexões de fundo cabalístico apontadas em todo o discurso analisado.

Com isso, é possível avançar na leitura e procurar perceber a morte como a impossibilidade da linguagem, sua opacidade. Mas como há nela um hálito divino, é pois, também, via de criação de novas vidas, novas significâncias - uma tradução em que o tradutor não busca representar o original, mas afetá-lo, recriá-lo7 .

O Gênese conta que a mulher foi criada a partir do momento que o homem, tendo já nomeado todos os outros seres, não conseguiu dar nome a si mesmo. Para tanto, ele é posto em sono profundo para que fosse retirada dele a costela que daria origem ao seu duplo. Os dois últimos versos do poema dizem: Porque assim é preciso/ para que tu vivas e, da mesma forma como acontece no poema, o livro termina com a

\footnotetext{
${ }^{7}$ Ver Benjamin, 2001. p. 188 - 215. No texto "A tarefa-renúncia do tradutor" percebe-se que conceito de tradução enquanto recriação pode ser aplicado, também, à leitura pretendida no caso de A obscena senhora $D$.
}

Brasiliana - Journal for Brazilian Studies. Vol. 1, n.1 (Sept. 2012). ISSN 2245-4373. 
morte. E através da morte - como do profundo sono do homem que mais tarde denominou-se Adão - chega-se uma definição do que seria Hillé.

Antes de morrer, porém, a senhora $D$ é surpreendida por uma visita bastante improvável, uma grande porca que invade sua casa fugida do quintal de alguém. E, ao precisar alimentar um outro ser vivo, vem-lhe de novo a irremediável necessidade de nomear, e como houvesse uma identificação entre elas, designou-a senhora P:

Tento sair da minha pulverescência, e olho longamente a senhora P. Me olha. É parda, soturna, medrosa, no lombo uma lastimadura, um rombo sanguinolento. Hoje pude me aproximar muito lenta, e como diria o sóbrio: pensei-lhe os ferimentos. Roxo-encarnado sem vivez este rombo me lembra minha própria ferida, espessa funda ferida da vida (Hilst, 2001, p. 88).

Irmanadas na mesma ferida - como se provenientes da mesma essência, da mesma "costela" - porca e louca se entendem (Hilst, 2001, p. 88), compartilham o mesmo nome - como no Gênese, "homem" e "mulher", vindos de "humano" e "humana". A criação do mundo via verbo se abre, finalmente, numa possibilidade para Hillé. Mesmo que o nome por ela designado seja mais um enigma de si mesma, senhora $P$, opaco, turvo, como mesmo ela era.

O homem, como "ser doador de nomes" (Benjamin, 1987, p. 141), é responsável pela dicotomia entre "nome próprio" e "nome comum". Hillé, ao nomear a si mesma e a sua semelhante, deixa o "nome próprio", marca de uma identidade única, em favor de apenas uma inicial que, na composição final, mais se assemelharia ao 
“comum". À porca, então senhora $P$, é dada uma identidade "própria", pois a semelhança a aproxima da humanidade.

O grande susto, de se ver, ao final, transmutada (traduzida?) em senhora $P$ faz com que sua derradeira busca tenha fim:

[...] os olhos um aquoso de incompreensão e de doçura, um sem-Deus sem-Deus hifenizado sempre, sem-Deus sem-Deus. Conheces o canto do pássaro sem-fim, senhora P? sem-fim, sem-fim, sem-fim nosso existir sem-Deus. E me vem que só posso entender a senhora $\mathrm{P}$, sendo-a. Me vem também, Senhor, que de um certo modo, não sei como, me vem que muito desejas ser Hillé, um atormentado ser humano. E SENTIR. Ainda que seja o aguilhão de um roxo-encarnado aparentemente sem vivez (Hilst, 2001, p. 88).

A metamorfose das senhoras é ocasionada pela necessidade de ser, de retomar alguma possibilidade de encontro entre a palavra e a coisa, como era na língua pré-babélica. Ou melhor dizendo, uma vez mais, nas palavras de Seligmann-Silva: "na palavra divina não há separação entre objeto denominado e o nome ou entre conteúdo e a forma; ela é criadora, portanto, ela é o próprio ser" (Seligmann-Silva, 1999, p. 82, grifos meus).

Ao compreender, finalmente, que a experiência com o inteligível não é suficiente para submeter o abstrato plano das sensibilidades ao da representação, vemlhe a lucidez: "E me vem que só posso entender a senhora P, sendo-a. Me vem também, Senhor, que de um certo modo, não sei como, me vem que muito desejas ser Hillé, um atormentado ser humano. E SENTIR"(Hilst, 2001, p.88). 
Assim, ao "ser" a "senhora P", Hillé adquire a (abrupta) compreensão, como se fosse um átimo de lucidez num ambiente turvo. E Deus (ou Porco-Menino), como se também pudesse ser Hillé, a definiu:

\section{Hillé era turva, não?}

\section{um susto que adquiriu compreensão.}

que cê disse, menino?

o que você ouviu: um susto que adquiriu compreensão. isso era Hillé.

Ahn. Cê é daqui, menino?

eu moro longe. Mas conheci Hillé muito bem.

como cê chama?

me chamam de Porco-Menino.

Por quê?

Porque eu gosto de porcos. Gosto de gente também.

Ahn (Hilst, 2001, p. 90, grifos nossos).

As interjeições que intercalam o diálogo expressam uma compreensão do que está sendo dito, curiosamente, contudo, elas enunciam um silêncio (como se houvesse uma pausa para a próxima enunciação e nesse tempo silencioso de espera se desse o entendimento do que estava sendo conversado), mas não um silêncio consternado, e sim cheio de significados, de comunicação. É nesse silêncio (nessa ausência plena) que está guardado o nome de Deus: Livrai-me, Senhor, dos abestados e atoleimados (Hilst, 2001, p. 90).

Como se já fosse um certo truísmo, a conclusão é o sigilo ostentado na linguagem ousada daquela senhora que, sendo uma grande porca acinzentada, portanto, 
sem voz representativa na linguagem das coisas, surpreendeu a si mesma ao sentir a grande linguagem calada dos homens.

\section{Referências}

Auercah, Erich. "A cicatriz de Ulisses". In: - Mimesis: a representação da realidade na literatura ocidental. 4. ed. São Paulo: Perspectiva, 1998. p. 1-20.

Benjamin, Walter. "A tarefa-renúncia do tradutor". Trad. Susana Kampff Lages. In: Heidermann, Werner (org.). Clássicos da teoria da tradução. Florianópolis: UFSC, Núcleo de Tradução, 2001. p. 188 - 215.

. "Sobre el lenguaje en general y sobre el lenguaje de los hombres". In: Sobre el programa de la filosofía futura. Tradução Roberto J. Vernengo. Caracas: Monte Ávila Editora, 1987.

Bíblia Sagrada. São Paulo: Loyola, 1994.

Bloom, Harold. Cabala e Crítica. Trad. Monique Balbuena. Rio de janeiro: Imago, 1991.

Derrida, Jacques. A escritura e a diferença. Trad. Maria Beatriz Marques Nizza da Silva. São Paulo: Perspectiva: 1995. . Torres de Babel. Trad. Junia Barreto. Belo Horizonte: Editora UFMG, 2002.

Eco, Umberto. A busca da língua perfeita. Trad. Antonio Angonese. Bauru, SP: EDUSC, 2002.

Foucault, Michel. As palavras e as coisas. Tradução Salma Tannus Muchail. São Paulo: Martins Fontes, 2002.

Hilst, Hilda. A obscena senhora D. São Paulo: Globo, 2001. . Exercícios para uma idéia. In: Exercícios. São Paulo: Globo, 2002.

Brasiliana - Journal for Brazilian Studies. Vol. 1, n.1 (Sept. 2012). ISSN 2245-4373. 
. Entrevista. In: Instituto Moreira Salles. HILDA HILST.

Instituto Moreira Salles. HILDA HILST. Cadernos de Literatura Brasileira, São Paulo, n. 8, out. 1999.

Merleau-Ponty, Maurice. "A linguagem indireta e as vozes do silêncio". In: O olho e o espírito. Tradução Paulo Neves e Maria Ermantina Galvão Gomes Pereira. São Paulo: Cosac \& Naify, 2004.

Oliveira, Maria Clara Castellões de. “O pensamento tradutório judaico: Franz Rosenzweig em diálogo com Benjamin, Derrida e Haroldo de Campos". 2000 - Tese (Doutorado em Letras: Estudos Literários) - Faculdade de Letras, Universidade Federal de Minas Gerais, Belo Horizonte.

Seligmann-Silva, Márcio. Ler o livro do mundo - Walter Benjamin: Romantismo e Crítica Poética. São Paulo: Iluminuras, 1999. 